\title{
PSYCHOSOCIAL ASPECTS OF ADJUSTMENT DISORDERS IN WOMEN
}

D0I: 10.36740/WLek202002127

\author{
Larysa 0. Herasymenko \\ UKRAINIAN MEDICAL STOMATOLOGICAL ACADEMY, POLTAVA, UKRAINE
}

\begin{abstract}
The aim is to study the psychosocial aspects of adjustment disorders in women.

Materials and methods: 54 women with diagnosed adjustment disorders (F43.2) who applied for advisory support were examined. The analysis of their anamnestic data with the help of a special questionnaire was performed, a clinical and psychopathological examination was conducted. To study various aspects of psychosocial maladjustment in this contingent of patients "The Stress Scale" by T.H. Holmes and R.H. Rahe (1967), "The Scale of Psychosocial Maladjustment” by L.0. Herasymenko, A. M. Skrypnikov and M. Rokeach methodology of studying of the value orientations (Fantalova 0.B. modification, 1992) were used.

Results: In $77.8 \%$ of cases a mixed type of maladjustment with dominance in the internal structure of factors of family and industrial maladjustment and in $29.6 \%$ a family maladjustment monovariant were identified. In most cases, the family and production variants were combined and a mixed variant of maladjustment was diagnosed. At the same time the most serious forms of maladjustment related to the sexual sphere. Analysis of the structure of psychosocial maladjustment of patients with adjustment disorders showed that the most typical manifestations of this disorder were the following: dissatisfaction with a sense of comfort $(75,95 \%)$, dissatisfaction with the psychological climate in the family $(62,03 \%)$ and with the period of marriage $(62,03 \%)$, dissatisfaction with psychological relationships with colleagues $(60,76 \%)$ and with the psychological relationship of the spouse $(60,76 \%)$ and a high multiplicity of irritation $(54,43 \%)$.

Conclusions: The leading factors of maladjustment among the examined women were the stress in subjectively significant areas of activity and the conflictual nature of the desirability and accessibility of basic life values.
\end{abstract}

KEY WORDS: adjustment disorders, psychosocial maladjustment

Wiad Lek. 2020;73(2):352-354

\section{INTRODUCTION}

Modern society with its rapid transformations puts the adaptive mechanisms of a person in a situation of critical tension. Information loads are increasing, and the psychological aspects of communicative activity come to the forefront [1]. All this leads to an increase in the prevalence and structural diversity of maladjustment states, putting forward the psychosocial aspects of this problem on the first roles [2]. Women are particularly vulnerable in this situation [3]. From the point of view of the system approach, psychic adaptation means a holistic, multidimensional and self-directed functional system, aimed at maintaining the sustained interaction of the individual with the environment [4].

In such a system all somatic, neuropsychic and socio-psychological components are closely interconnected. Changes in at least one of them cause the need for the inclusion of compensatory mechanisms, with a lack of which there is a maladjustment $[5,6]$.

\section{THE AIM}

Aim is to study the psychosocial aspects of adjustment disorders in women.

\section{MATERIALS AND METHODS}

54 women with diagnosed adjustment disorders (F43.2) who applied for advisory support to the staff of the Department of Psychiatry, Narcology and Psychology of the Higher State Educational Establishment of Ukraine "Ukrainian Medical Stomatological Academy" were examined. All of them gave informed consent to participate in the study.

The analysis of their anamnestic data with the help of a special questionnaire was performed, a clinical and psychopathological examination was conducted. To study various aspects of psychosocial maladjustment in this contingent of patients "The Stress Scale" by T.H. Holmes and R.H. Rahe (1967), "The Scale of Psychosocial Maladjustment" by L.O. Herasymenko, A.M. Skrypnikov and M. Rokeach methodology of studying of the value orientations (Fantalova O.B. modification, 1992) were used.

\section{RESULTS AND DISCUSSION}

In accordance with the aim of this study, an analysis of the stressful load of patients using the T.H Holmes and R.H. Rahe method (1967) created to self-assess the patient's current level of stress over the last year and a forecast for the development of psychogenic pathology was performed. The following data are received: 
Table I. The results of the analysis of the «Scale of Psychosocial Maladjustment» in women with adjustment disorders

\begin{tabular}{|c|c|c|c|c|c|c|c|c|c|c|}
\hline \multirow{3}{*}{ Maladjustment Options } & \multicolumn{10}{|c|}{ Gravity } \\
\hline & \multicolumn{2}{|c|}{ Adjustment } & \multicolumn{2}{|c|}{ Risk Group } & \multicolumn{2}{|c|}{ Mild } & \multicolumn{2}{|c|}{ Average } & \multicolumn{2}{|c|}{ Severe } \\
\hline & abs & $\%$ & abs & $\%$ & abs & $\%$ & abs & $\%$ & abs & $\%$ \\
\hline Economic & 8 & 14,8 & 24 & 44,4 & 14 & 25,9 & 2 & 3,7 & 8 & 14,8 \\
\hline Production & 5 & 9,3 & 10 & 18,5 & 19 & 35,2 & 8 & 14,8 & 12 & 22,2 \\
\hline Family & - & - & 11 & 20,4 & 18 & 33,3 & 15 & 27,8 & 10 & 18,5 \\
\hline Information & 12 & 22,2 & 21 & 38,9 & 6 & 11,1 & 11 & 20,4 & 4 & 7,4 \\
\hline Communication & 16 & 29,6 & 14 & 25,9 & 12 & 22,2 & 12 & 22,2 & - & - \\
\hline Sexual & 8 & 14,8 & 15 & 27,8 & 7 & 12,9 & 10 & 18,5 & 14 & 25,9 \\
\hline
\end{tabular}

Very low stress load (less than 150 points) - no case. Low stress load (150-199 points) - 5 (9.3\%) women. Threshold stress load (200-299 points) - 16 (29.6\%). High stress load (300 or more points) - 33 (61.1\%) women.

For most of the examined women, a high stress load was characteristic during the last year as a precondition for the emergence of adjustment disorders. The structure and characteristics of psychosocial maladjustment in women with adjustment disorders were studied by the method "Scale of Psychosocial Maladjustment". The result is summarized in Table I.

In $77.8 \%$ of cases a mixed type of maladjustment with dominance in the internal structure of factors of family and industrial maladjustment and in $29.6 \%$ a family maladjustment monovariant were identified. In most cases, the family and production variants were combined and a mixed variant of maladjustment was diagnosed. At the same time the most serious forms of maladjustment related to the sexual sphere. The largest proportion of severe manifestations associated with somatic reactions such as tremor, sweating, palpitations, headaches, sleep and appetite disorders, etc., accounted for cases of family psychosocial maladjustment that arose in response to unresolved family situations conflicts.

Analysis of the structure of psychosocial maladjustment of patients with adjustment disorders showed that the most typical manifestations of this disorder were the following: dissatisfaction with a sense of comfort (75,95\%), dissatisfaction with the psychological climate in the family $(62,03 \%)$ and with the period of marriage $(62,03 \%)$, dissatisfaction with psychological relationships with colleagues $(60,76 \%)$ and with the psychological relationship of the spouse $(60,76 \%)$ and a high multiplicity of irritation (54,43\%).

M. Rokeach value orientation method of studying (Fantalova O.B. modification, 1992) studies the content side of the personality orientation, which forms the basis of the attitude towards the surrounding world and the core of the activity of life, the basis of the life concept and the "phylosophy of life."

According to the data obtained, women with adjustment disorders gave preference to love, interesting work and happy family life among the value orientations. The analysis of the examined patients hierarchy of values from the point of view of their accessibility indicates that subjectively the most significant values for the maladjusted women (interesting work, love, happy family life) had low accessibility which created the situation of conflict (discrepancy index) due to inaccessibility of the most important vital values. The most accessible values to maladjusted women were the beauty of nature, friends, creativity but as their subjective importance is relatively low it also created a high discrepancy index by the type of satiety.

In general, the high rate of discrepancy of importance with accessibility of basic values (interesting work, love, happy family life) correlates with the data on the leading role of a mixed version of psychosocial maladjustment (with dominance of professional and family factors) in women of this group.

The index of the discrepancy between the importance and accessibility of life values was established for each patient individually. As a result of the data processing it was established that $81.5 \%$ of the examined are characterized mostly by the conflict type of the relationship of terminal life values, $90.9 \%$ of them have a deficiency conflict, and $9.1 \%$ are predominantly conflict because of satiety.

The analysis of the most common factors in the formation of maladjustment in the examined women has been carried out. These include high stress loads, intrapersonal and interpersonal conflicts, violations of sexual and communicative functions, as well as a high level of conflict between the desirability and accessibility of basic vital values.

The family form of maladjustment was mainly developed as a result of the discrepancy between expectations and the real situation in the family relationship, the inability to stay in the current relationship and the inability to find effective ways to resolve the conflict situation. Interpersonal and interpersonal conflicts, the most frequent cause of which was the absence of a mutual feeling of love and respect in a married couple, presence of one of the spouses of character traits, causing non-acceptance in another, discrepancy of moral, ethical and aesthetic attitudes, of role behavior, sexual aversion and others were determined as the main reason of its development. Destructive tendencies in the solution of such conflicts contributed to the development of psychosocial maladjustment in the family variant.

Violations of the communicative and sexual function in the case of family maladjustment and communicative difficulties in the case of industrial (official) maladjustment were a significant factor in the formation of conflicts and the maladjustment situation among the examined women. These factors were particularly important in the case of the domination of family values or the goal of professional growth, respectively. Among the causes of the violation of sexual function were both factors of a somatic nature, and sexual aversion. 
Against the background of the inherent high level of personal anxiety and introversion in most of the examened women this led to the frustration of the actual needs for health, love, happy family life, which were central to their value system. The examined patients were inclined to think about the causes of unsuccessful marriage, the prospects of divorce, and the analysis of family conflicts, which accompanied by a decrease in mood, sleeping, appetite, and capacity for work impairment, which additionally complicated the adaptation in a significant part of the cases, contributing to the emergence of a "vicious circle".

In some patients the maladjustment of family relationships reached the degree of aversion which involved the psychological and sexual spheres including both conscious and unconscious mechanisms. The psychological and sexual forms of the aversion were evident both in isolation and in the united form. Sexual aversion in isolated form occured with a short duration of maladjustment phenomena and turned into a more global process in the following stages involving a wider range of spheres of activity in the absence of corrective effects.

Although most of the examined women got married or started a relationship with a partner with a feeling of love and friendship, however, for the period of the examining, in case of diagnosis of family maladjustment, all of them reflected on the prospects for divorce, already initiated or completed this process. This situation confirms the destructive impact of the family variant of psychosocial maladjustment on marriage and its stability once again.

The most important and widespread factor of professional maladjustment was the discrepancy of real opportunities to the system of values and requirements related to professional activities. The most typical situation with the expressive dominance of the interests of professional growth in the value system on the background of the unachievably high level of requirements that were put forward in connection with the professional activities of the examined women can be recognized. Discrepancy in the form of dominance of domestic interests against the background of high demands on professional activity was observed less often.

The accompanying somato-vegetative manifestations of the adjustment disorder weakened their functional capabilities, made them vulnerable and insecure. They had obsessional stereotyped thoughts about their own failures in the professional sphere, the need to «change something», search for prospects, etc., that were accompanied by negative emotional feelings and further deterioration of working capacity.

The inability to meet the employer requirements created a rather serious conflict with the expectation of receiving «interesting» work and «material security» as a result of activity. Inferiority feeling and self-doubt complemented the existing background symptomatology and deepened the crisis phenomena of professional maladjustment.

Communicative difficulties with management and colleagues played an important role on a number of occasions. Ability to formulate desires, requirements and expectations clearly and absence of informal communication which would complement a purely formalized relationship, compensating for possible professional conflicts, is absent in patients.
The wrong professional choice made inappropriately or under the pressure of the immediate environment, parents or circumstances played an important role in some cases. The choice in favor of the activity in the natural field in conditions of predisposition to the humanitarian sphere and vice versa is a typical example of such a situation.

\section{CONCLUSIONS}

To sum up it is necessary to note that the leading factors of maladjustment among the examined women were stressful loads in subjectively significant spheres of activity and the conflicting nature of desirability and accessibility of basic life values.

The obtained data can be used to construct an effective system of rehabilitation of women with adjustment disorders and methods of preventive work with them.

\section{REFERENCES}

1. Shieds J. Handbook of abnormal psychology. London: Pitman medical publishing; 1973.603p.

2. Orban-Lembryk L.E. Sotsial'na psihologiya. Kyiv: Academvydav; 2005. $448 \mathrm{p}$.

3. Breslau N., Kessler R., Howard D., Schultz L., Davis G., Andreski P. Trauma and posttraumatic stress disorder in the community. Archives of General Psychiatry. 1998; 55: 626-632.

4. Chaban 0.S., Khaustova 0.0. Dezadaptatsiya lyudini v umovah suspil'noyi krizi: novi sindromi ta napryamki yih podolannya. Journal of Psychiatry and Medical Psychology. 2009; 3: 13-21.

5. Ono Y., Yoshimura K., Mizushima H. Gender differences of somatoform symptoms. Abstracts XWorld Congress of Psychiatry: Madrid. 1996; 1:78.

6. McGrathE., Keita G.P.,Stickland B.R., Russo N.F.Women and depression:Risk factors and tratment issues. Washington: Am. Psychol. Ass., 1990.123 p.

ORCID and contributionship:

Larysa O. Herasymenko - 0000-0001-9002-3641 $1^{A, B, C, D, E, F}$

Conflicts of interest:

Author declare no conflict of interest.

\section{CORRESPONDING AUTHOR \\ Larysa 0. Herasymenko \\ Ukrainian Medical Stomatological Academy \\ 1 Medychna Str., Poltava 36013, Ukraine \\ e-mail: larysaherasymenko@gmail.com}

Received: 03.07 .2019

Accepted: 15.11 .2019

A - Work concept and design, B - Data collection and analysis, C - Responsibility for statistical analysis,

D-Writing the article, $\mathbf{E}$-Critical review, $\mathbf{F}$ - Final approval of the article 